\section{Infliximab-induced intertriginous psoriasis in patient with Crohn's disease}

\author{
Federica Mola, Alberico Motolese \\ Department of Dermatology, Circolo \\ Hospital and Macchi Foundation, \\ Varese, Italy
}

\begin{abstract}
Tumor necrosis factor- $\alpha$ (TNF $\alpha$ ) inhibition is an effective treatment of moderate-to-severe psoriasis and other diseases (rheumatoid arthritis, ankylosing spondylitis, psoriasis or Crohn's disease). We report a case of a 32years-old patient affected by Crohn's disease since the age of 25 who started infliximab infusion after four years of treatment with prednisone and azathioprine per os without improvement. After the fifth infusion of infliximab, he developed a form of intertriginous psoriasis which was approached with topical steroid cream. The patient never presented psoriasis in the past. New onset of psoriasis in patients without history for skin diseases (as in our case) is a quite uncommon complication of TNF $\alpha$ inhibitor therapy. The increased production of IFN $\alpha$ during TNF $\alpha$ inhibitor therapy is a possible pathophysiologic explanation for this paradoxical effect of the anti-TNF $\alpha$.
\end{abstract}

\section{Introduction}

Tumor necrosis factor- $\alpha$ (TNF $\alpha)$ is a proinflammatory cytokine produced by different cell types (activated T lymphocytes, keratinocytes, Langerhans cells, endothelial cells, cardiac myocytes, adipose tissue etc.) and is involved in the pathogenesis of psoriatic skin lesions. TNF $\alpha$ inhibitors have become established agents in the treatment of inflammatory diseases and have shown to be of great benefit in many inflammatory diseases (rheumatoid arthritis, ankylosing spondylitis, psoriasis or Crohn's disease). ${ }^{1}$

\section{Case Report}

We report a case of unexpected induction of Psoriasis due to the use of intravenous TNF $\alpha$ inhibitor.

A 32-years-old male patient with recalcitrant Crohn's disease of the ileum and descending colon (treated without improvement with pred- nisone, mesalazine and azathioprine per os) started treatment with infliximab at the dose of $5 \mathrm{mg} / \mathrm{Kg}$ at the week $0,2,6$ and afterwards every 14 weeks. After the fifth infusion he developed erythematous patches with peripheral scaling in the axillary folds and inguinal areas, suggesting the diagnosis of flexural psoriasis (Figure 1). The face and the neck also presented a form of sebopsoriasis (Figure 2). The patient never had psoriasis in the past, and he did not have a familiar history of any skin disease. No signs of infection were shown.

The skin biopsy showed psoriasiform hyperplasia, papillary dermal edema with parakeratosis and intracorneal microabscesses of neutrophils (Figure 3).

The infliximab infusion was continued (seeing the good response of Crohn's disease) and a clinical skin improvement was achieved after 40 days of topical steroid treatment.

An expanding literature of experience with anti TNF $\alpha$ associated psoriasis is providing abundant information about this paradoxical effect. Many cases are described. The first published report of this association appeared in 2004 and concerned the development of symmetrical psoriasiform plaques in a patient treated with infliximab for Crohn's disease. ${ }^{2}$ Subsequently plaque, guttate, and pustolar psoriasis have all been noted, and palmoplantar pustolar disease appears to be more common than idiopathic psoriasis, accounting for up to the $50 \%$ of reported cases. Flexural psoriasis and sebopsoriasis are a rare form of presentation. In fact, to our knowledge, ther are only two articles describing cases of flexural psoriasis during infliximab treatment for Crohn's disease. ${ }^{3,4}$

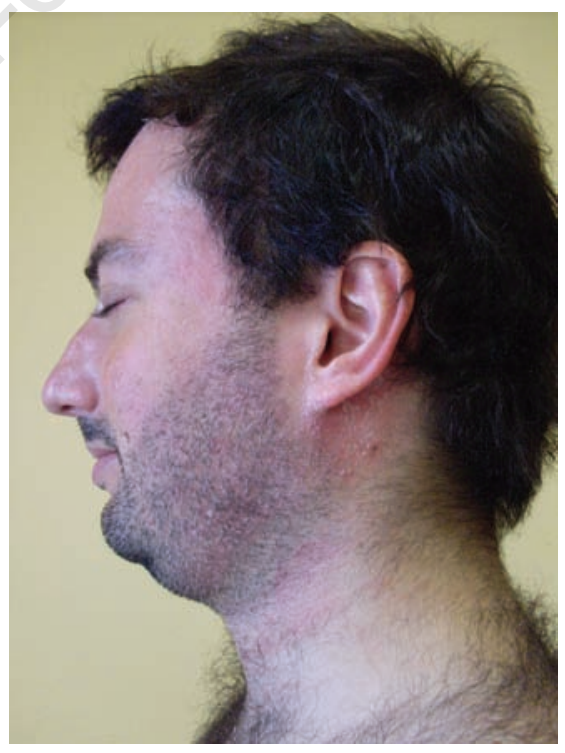

Figure 1. Erythematous patches with peripheral scaling in the axillary folds, suggestive for the diagnosis of flexural psoriasis
Correspondence: Federica Mola, Department of Dermatology, Circolo Hospital and Macchi Foundation, viale Borri 75, Varese, Italy.

Tel. +39.349.2611869.

E-mail: federicamola@yahoo.it

Key words: tumor necrosis factor- $\alpha$, psoriasis, crohn's disease.

Received for publication: 6 June 2011.

Accepted for publication: 12 September 2011.

This work is licensed under a Creative Commons Attribution NonCommercial 3.0 License (CC BYNC 3.0).

(C) Copyright F. Mola and A. Motolese, 2011 Licensee PAGEPress, Italy

Dermatology Reports 2011; 3:e40

doi:10.4081/dr.2011.e40

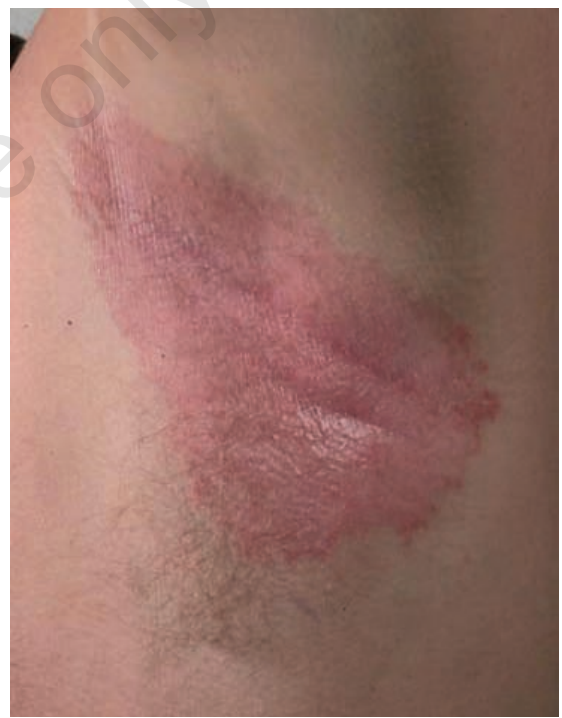

Figure 2. Typical erithemato-desquamative patches on the face and neck in sebopsoriasis.

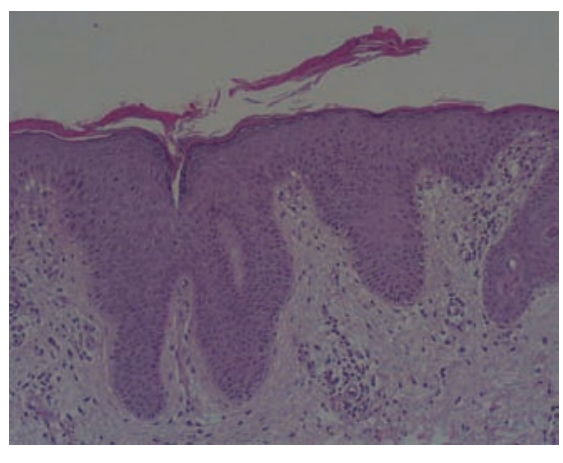

Figure 3. Histologic evaluation demonstrates psoriasiform hyperplasia, papillary dermal edema with parakeratosis and intracorneal microabscesses of neutrophils. 
It is well recognized that blocking TNF $\alpha$ may actually favour specific autoimmune phenomena and may activate autoreactive T cells. In addition, with particular relevance to the skin, it may upregulate interferon (IFN)- $\alpha$ activity. ${ }^{5}$ Immunologically this is not unexpected because TNF $\alpha$ is known to negatively regulate the maturation and function of plasmocytoid dendritic cells, which are the major source of IFN- $\alpha$. Therapeutic inhibition of TNF $\alpha$ signaling would increase IFN $\alpha$ activity and could trigger psoriasis in genetically susceptible

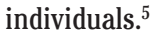

On the other hand, some cases can be diagnosed as an adverse drug reaction and may contribute to stop the treatment. In literature two-thirds of patiens who simply continue anti TNF $\alpha$ therapy improve or resolve the skin disease with steroid treatment. The decisions need to be based on individual circumstances as the extent and severity of the disease, the efficacy of the anti TNF $\alpha$ in treating the condition for which it was initiated and the availability of realistic therapeutic alternatives. ${ }^{5}$

\section{References}

1. Wollina U, Hansel G, Koch A, et al. Tumor necrosis factor-alpha inhibitor-induced psoriasis or psoriasiform exanthemata: first 120 cases from the literature including a series of six new patients.Am J Clin Dermatol 2008;9:1-14.

2. Baeten D, Kruithof E, Van den Bosch F, et al. Systematic safety follow up in a cohort of 107 patients with spondyloarthropathy treated with infliximab: a new perspective on the role of host defence in the pathogenesis of the disease? Ann Rheum Dis $2003 ; 62: 829-34$

3. Peramiquel L, Puig L, Dalmau Jricart E, et al. Onset of flexural psoriasis during infliximab treatment for Crohn's disease. Clin Exp Dermatol 2005; 30:713-4.

4. Avila Alvarez A, Garcia-Alonso L, Solar Boga A, Garcia-Silva J. Flexural Psoriasis induced by infliximab and adalimumab in a patient with Crohn's disease. An Pediatr (Barc) 2009; 70:278-81.

5. Shale M, Ghosh S. Learning the lessons of antitumour necrosis factor therapy-associated psoriasis. Can J Gastroenterol 2009; 23:674-6. 